\title{
Harvesting of Natural Rubber Trees (Hevea brasiliensis) Affected with Tapping Panel Dryness (TPD)
}

\author{
S.A.A.P.Kumari ${ }^{1}$ and R.C.W.M.R.A. Nugawela ${ }^{2 *}$
}

\begin{abstract}
Incidence of Tapping Panel Dryness (TPD) is generally high in relatively high yielding rubber (Hevea brasiliensis) clones and is characterized by partial followed by complete cessation of latex flow upon tapping leading to a severe crop loss. If TPD is left unchecked and untreated it will lead to significant economic losses to rubber growers. To-date there is no reliable method recommended to either cure or to obtain economic yields from such rubber trees. This study revealed that TPD trees rested during noncropping months of a year had developed the capacity to yield around $25 \%$ of the yield potential (gtt) of a healthy tree when tapped during the cropping months in a year. And agrochemical called "DRC +3 " and $1 \%$ ethephon were found to be capable of increasing the gtt of TPD trees by about 50 to $75 \%$ during the cropping season of a year. Further, it became apparent that through this method $60 \%$ of the length of the tapping cut of TPD trees became productive. Though the Dry Rubber Content (DRC) of latex declined with the use of both chemicals, an increased latex volume after the application of the chemicals sustained the yield throughout the study period. Hence it could be concluded that TPD trees rested from tapping during the low cropping season of a year could be harvested during cropping months together with the use of chemicals tested to achieve up to $50 \%$ of the gtt of a healthy tree.
\end{abstract}

Keywords: Dry rubber content, Ethephon, Hevea brasiliensis, Tapping panel dryness

\footnotetext{
${ }^{1}$ Lalan Rubbers (Pvt) Ltd., Pitiakande Group, Muwankande Estate, Mawathagama, Sri Lanka

${ }^{2}$ Department of Plantation Management, Faculty of Agriculture and Plantation Management, Wayamba University of Sri Lanka *asokanugawela@yahoo.com
}

\section{INTRODUCTION}

Incidence of Tapping Panel Dryness (TPD) in rubber (Hevea brasiliensis) is characterized by late dripping and then followed by partial and complete cessation of latex flow from the tapping cut. Besides cessation of latex flow, terminal symptoms like bulging, necrosis and cracking of the bark have been observed in TPD affected trees. This issue has led to severe losses in natural rubber production in all rubber growing countries. High yielding rubber clones are reported to be more susceptible to TPD. It is estimated that TPD leads to approximately $15-20 \%$ decrease of potential yield (Jiang and Zhou, 1997). Also, TPD trees are categorized into two, i.e. reversible and irreversible depending on the ability to yield upon tapping of such trees after a period of tapping rest (Jacob et al., 1994). However, symptoms of TPD trees in terms of morphological features and ability of latex production are rather complicated. This is evident by trees with partial and fully dryness, trees with and without bark out-growth and bark cracks and trees recovered from dryness.

There are many factors believed to cause TPD. Harvesting trees at intensities higher than the recommendation, harvesting during defoliating period, tapping of wet panels and non-application of fertilizer are some of them (Gohet et al., 1997). A nonrandom distribution of TPD trees in the plantations is also reported suggesting possible effect of edaphic factors on the incidence (De Soyza et al., 1983).

Recent studies have also revealed that rubber trees in the lowest and highest 
girth categories are relatively more prone to TPD than rest of the trees (Perera and Nugawela, 2011, Gamage and Nugawela, 2012). Further, it is observed that TPD is even evident in well managed plantations and also soon after the commencement of tapping in a new rubber clearing. These studies and observations suggest that incidence of TPD in certain trees is not caused by either over exploitation or poor agro-management or a combination of them. In Sri Lanka the total land extent under rubber is 126, 000 ha and 101, 000 ha of it are under tapping (Central Bank Annual Report, 2012). If the incidence of TPD in the country is not resolved that will lead to severe losses in natural rubber whilst resulting in economic losses to growers. This is true at both national and global levels as well.

Naturally, the yield potential in rubber trees is high during the period of September to January in the following year. In this study, tapping was commenced on TPD trees left without being attempted to be exploited for latex, during the cropping period of the year. Further, an agrochemical recommended to cure TPD, "DRC +3 " were tested together with ethephon to check their ability to either cure or facilitate the latex flow of such rubber trees.

\section{MATERIALS AND METHODS}

\section{Location}

The study was carried out at Muwankande Estate, Mawathagama in Kurunegala district which belongs to the mid country intermediate zone of the North Western Province where annual rainfall ranges from 1750 to $2500 \mathrm{~mm}$ whilst the annual mean temperature ranges from $24^{\circ} \mathrm{C}$ to $31{ }^{\circ} \mathrm{C}$. The study was also replicated at Mahaoya Estate, Dehiowita in the Kegalle district falling into the wet zone with an annual rainfall of over $3000 \mathrm{~mm}$ and a temperature range of 25 to $30{ }^{\circ} \mathrm{C}$.

\section{Experimental Area}

At Muwankande Estate, two fields planted with clone RRIC 121 (a clone recommended to be tapped every other day, i.e., $d / 2$ clone) were selected for the study. One of the two fields was tapped on panel BO -2 and the other on renewed bark, i.e. panel B1-1. A field planted with same clone from the Mahaoya Estate to replicate the study. All fields selected for the study were tapped at 1/2S d/3 tapping system, i.e., half spiral of the tree, tapped once in three days.

\section{Treatments \\ Muwankande Estate}

In the virgin bark tapped field, data were collected from three tapping blocks tapped by the same harvester on a $d / 3$ system. In all three tapping blocks the tapping of TPD affected trees were commenced in September 2012.

In renewed bark field, 45 TPD trees were selected randomly from each of the three tapping blocks tapped by one harvester to test the following treatments. The treatments were introduced randomly to the trees identified for the study.

Treatment $1\left(\mathbf{T}_{\mathbf{1}}\right)$ - "DRC +3 " *

(ga, 1g/tree/application, 1/5days)

Treatment 2 ( $\left.\mathbf{T}_{2}\right)$ - Ethephon $1 \%$

(ba, 1.6g/tree/application, 1/30days)

Treatment $3\left(\mathbf{T}_{3}\right)$ - Control

*Manufacturer - Agroe and Fertilizers, SDN. BHD. Malaysia

\section{Mahaoya Estate}

Thirty trees affected with TPD and ten healthy trees were selected randomly from each of the three tapping blocks tapped by one harvester. The following treatments were introduced with ten trees per each treatment. 
Treatment $1\left(\mathbf{T}_{\mathbf{1}}\right)$ - Healthy trees

Treatment 2 ( $\left.\mathbf{T}_{2}\right)$ - TPD + 1\% ETH (ba, $1.6 g, 1 / 30$ days)

Treatment 3 ( $\left.\mathbf{T}_{3}\right)$ - TPD + 1\% "DRC +3" (ba, 1g, 1/5days)

Treatment $4\left(\mathbf{T}_{4}\right)$ - TPD

\section{Data Collection}

Prior to the introduction of the treatments, of the trees selected for the study, the girth at a height of $150 \mathrm{~cm}$ from the union, length of the tapping cut, length of the yielding section of the tapping cut, latex volume and its dry rubber content were determined. Subsequent to the introduction of treatments, length of the yielding section of the tapping cut (once a month), latex volume and scrap yield of each tree at every tapping were measured. Also, the latex of different treatments was pooled separately for the determination of the DRC using the Laboratory method.

\section{Statistical Analysis}

Data were analyzed by ANOVA using statistical software Minitab 15 and Statistical Analysis System, 2009.

\section{RESULTS AND DISCUSSION}

Yield Of TPD Affected and Healthy Trees in the Virgin Bark Tapped Fields

Though the yield grams/tree/tapping (gtt) of TPD affected trees in the virgin bark area were about $25 \%$ of that of the healthy trees it was maintained throughout the experimental period, i.e. September to January in the following year. Hence, it is apparent that the TPD affected trees are able to produce yields up to $25 \%$ of the healthy trees during the cropping months of a year (Figure 1).

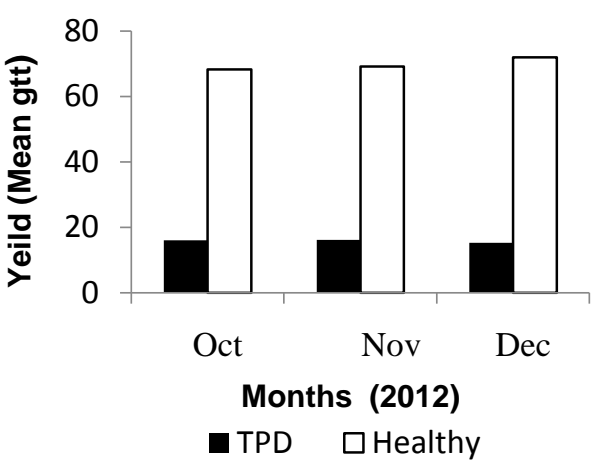

Figure 1. Yield (mean gtt) of TPD affected and Healthy trees in the virgin bark field.

Yield of TPD Affected and Healthy Trees in the Renewed Bark Tapped Field at Muwankanda Estates

TPD trees assigned with different treatments yielded similarly in September prior to introducing them (Table 1). Subsequent yields were significantly high in TPD trees treated with "DRC +3" (Manufacture: Agroe and Fertilizers, SDN. BHD., Malaysis), the agrochemical recommended to cure TPD trees and 1\% ethephon (Table 1 ). The yield increase over the untreated TPD trees was almost 50\%. However, though the trees treated with $1 \%$ ethephon yielded higher than the trees treated with the agrochemical recommended to cure TPD the difference was not significant. Also, it is evident that the yield of control and $1 \%$ ethephon treated trees prevailed whilst the yield of the agrochemical treated trees showed a gradual decline.

In all three treatments the dry rubber content of latex (DRC) declined with time. However, this decline was more pronounced in the trees treated with the agrochemical "DRC +3 ". The decline in DRC was least in the control trees (Figure. $2)$. The DRC of treated TPD trees was well above $30 \%$, indicating that the trees were not over exploited and were not under any stress condition. 
Table 1. Pre and post treatment yields of trees affected with TPD and tapped on renewed bark

\begin{tabular}{cllll}
\hline \multirow{2}{*}{ Treatment } & \multicolumn{4}{c}{ Mean Yield (gtt) } \\
\cline { 2 - 5 } & Sep. & Oct. & Nov. & Dec. \\
\hline 1 & $12.05^{a}$ & $25.15^{\mathrm{b}}$ & $24.2^{\mathrm{b}}$ & $21.45^{a}$ \\
2 & $15.05^{a}$ & $33.85^{\mathrm{b}}$ & $28.45^{\mathrm{b}}$ & $30.1^{\mathrm{b}}$ \\
3 & $14.45^{a}$ & $18.6^{a}$ & $19.65^{a}$ & $21.24^{a}$ \\
\hline
\end{tabular}

Same letters indicate non significance at $P<0.05$ September - Pretreatment yield

October, November and December - Post Treatment yields

The relatively low gtt in control trees could be due to the high DRC and hence less flow time due to rapid plugging of cut latex vessels. This is further confirmed by the low latex volume of these trees. Ethephon delays the plugging reaction and hence this could be the mode of action in increasing the gtt of TPD affected trees when treated with the same. The active ingredient/s of the "DRC +3" is not known and hence the possible mechanism from which the yields of TPD trees are enhanced cannot be explained.

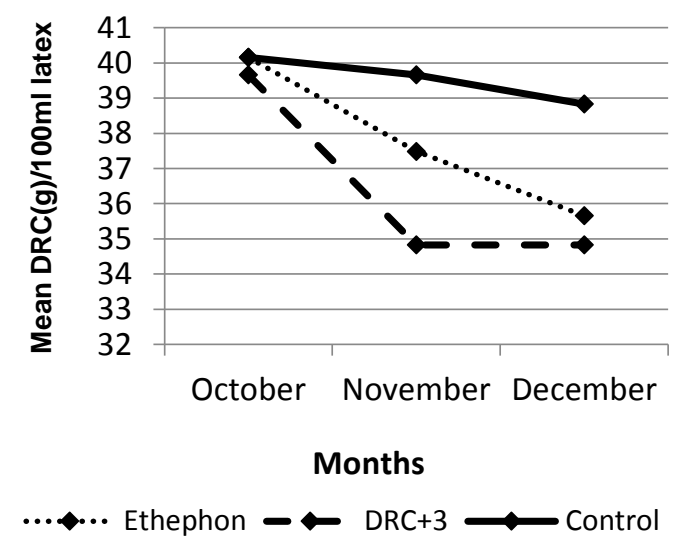

Figure 2. The effect of different treatments tested on the DRC of latex.

In all treatments the DRC was high during the initial stages of the trial but reduced gradually with time. The magnitude of the reduction in DRC is low in control trees compared to other treatments. A high DRC was maintained in control trees throughout the experimental period. But the DRC declined gradually with other treatments.

The selected TPD trees for the trial were untapped during the previous noncropping period. The high DRC level that prevailed during the initial period of the study could be attributed to this. However, with continuous tapping and the introduction of the treatments DRC had reduced gradually. Though the DRC declined, the resulting high latex volume ensured a stable mean yield during the study period (Table 1).

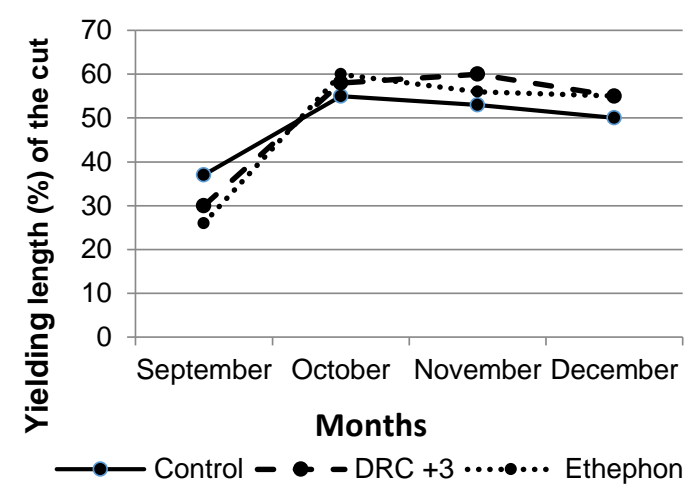

September - Pre-treatment effect

October, November and December - Post-treatment effect

Figure 3. The effect of different treatments on the yielding fraction (\%) of the total length of tapping cut

With the commencement of tapping TPD trees, the yielding section of the tapping cut gradually increased (Figure 3). Initially the yielding section was around $30 \%$ of the tapping cut but after one month of continuous tapping it had increased up to $55-60 \%$. The increase in yielding section was greater in treated trees than in the control (Figure 3). Further, the yielding fraction of the cut sustained supporting the sustainability of the yields achieved during the study period. 
In control trees, though the yielding fraction of the tapping cut increased there was no corresponding gain in rubber yield. However, in the treated trees a corresponding gain in yield was evident. This confirms that the yield gain from treatments is due to lowering of plugging index, resulting increased latex volume.

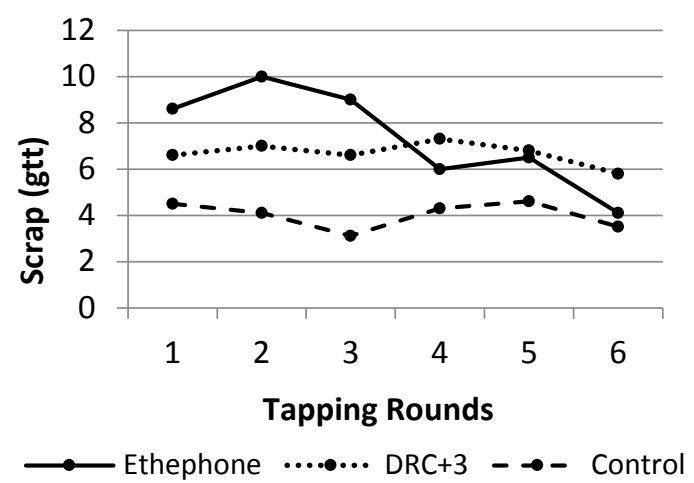

Figure 4. The effect of different treatments on the scrap yield

\section{Yield of TPD Affected and Healthy Trees in Virgin Bark Tapped Field at Mahaoya Estate}

Data collected during the month of December reveals that Ethephon had significantly increased the gtt of TPD trees (Table 2). The gtt increase is about $74 \%$ and it is $65 \%$ of the healthy trees.

Table 2. Effect of $1 \%$ ethephon and "DRC +3 " on the yield of TPD trees

\begin{tabular}{ll}
\hline Treatment & gtt \\
\hline $\mathrm{T}_{1}$ & $49.5^{\mathrm{a}}$ \\
$\mathrm{T}_{2}$ & $32.5^{\mathrm{b}}$ \\
$\mathrm{T}_{3}$ & $23.4^{\mathrm{bc}}$ \\
$\mathrm{T}_{4}$ & $18.7^{\mathrm{c}}$
\end{tabular}

(Treatments with same letter are not significantly different at $p<0.05$ )

The gtt increase due to "DRC +3 " is not significantly different from the untreated TPD trees. Scrap yields were generally higher in the "DRC +3 " and ethephon treated trees than in the control trees (Figure 4). Among the treatments, $1 \%$ ethephon treated trees recorded the highest scrap yield. This could be due to the reduction in the plugging index through ethephon. During each round of stimulation the scrap levels were highest soon after stimulation and then it declined as ethephon effect declined with time. However, with "DRC +3 " been applied at seven days interval the scrap levels prevailed during the study period. Relatively low latex volumes and high DRC levels than in treated trees would have led to low scrap levels in control trees (Figure 4).

\section{CONCLUSION}

The study reveals that TPD trees could yield about $25 \%$ of the healthy trees during the cropping months of a year. Application of either the agrochemical, "DRC +3", recommended to cure TPD or $1 \%$ ethephon, further increased the yields of TPD trees. The yield increase was more pronounced in ethephon treated trees and the increase was about 50 to $75 \%$. When TPD trees were tapped during the cropping months about $60 \%$ of the length of the tapping cut was found to be productive. Further, in treated trees the plugging index had reduced as evident by increased latex volume and a lower DRC. The yields of TPD trees in all treatments sustained during the study period. "DRC +3 " is recommended to be applied at weekly intervals whilst ethephon was applied at monthly intervals. Considering the low application cost and relatively high yield it could be concluded that TPD trees could be harvested during cropping months with the use of $1 \%$ ethephon. 


\section{ACKNOWLEDGEMENT}

Authors wish to express their gratitude to Group Senior Manager, Mr. Indranath Senanayaka, and Manager, Mr. Mahesh Kurukulasooriya of the Pitiakande Group. The cooperation extended by the field officer, Mr. M.C.K. Gunathilake and all staff members at Muwankande Estate are also appreciated.

\section{REFERENCES}

Central Bank Annual Report, (2012). Central Bank of Sri Lanka, Colombo 01.

De Soyza, A.G.A., Samaranayake, C., Abeywardena, V., Jayarathna, A.H.R. and Wilbert, S. (1983). A survey on the incidence and pattern of distribution of the brown bast disease of Hevea in Sri Lanka. Journal of the Rubber Research Institute of Sri Lanka, 61, 1-6.

Gamage, K. G. E. M., and Nugawela, R. C. W. M. R. A (2012). The impact of Vegetative Growth on the Incidence of Tapping Panel Dryness (TPD) in Hevea brasiliensis, Proceeding of $12^{\text {th }}$ Agricultural Research Symposium, Wayamba University of Sri Lanka.

Gohet, E., Dian, K., Prevot, J. C., Obouayeba, S., Clement, A., d'Auzac, J., Keli, J. Z. and Jacob, J. L., (1997). Relation between clone type, latex sucrose content and the occurrence of tapping panel dryness in Hevea brasiliensis. Proceedings of Workshop on tapping panel dryness in Hevea brasiliensis, (Hainan, China), 29-30 April 1997. 21-27.

Jacob, J. L., Prevot, J. C. and Lacrotte, R. (1994). L'encoche seche chez Hevea brasiliensis, Plantations Recherche Development, 1, 15-24.
Jiang, J. S. and Zhou, Z. Y. (1997). Prospects of science and technology for natural rubber in China. Chinese Journal of Tropical Crops, 21, 1 - 7.

Perera, E. P. and Nugawela, A. (2011). Influence of plant girth on the incidence of tapping panel dryness in Hevea brasiliensis. Proceedings of the $11^{\text {th }} \quad$ Agricultural Research Symposium, Wayamba University of Sri Lanka, 285-287. 